\title{
Systematic Review \\ The Role of Prehospital REBOA for Hemorrhage Control in Civilian and Military Austere Settings: A Systematic Review
}

\author{
Ching Nga Chan ${ }^{1}$, Bryar Kadir ${ }^{2}$ (D) and Zubair Ahmed 1,3,4,*(D) \\ 1 Institute of Inflammation and Ageing, University of Birmingham, Edgbaston, Birmingham B15 2TT, UK; \\ cookingmicmic@hotmail.com \\ 2 Cancer Research UK Clinical Trials Unit (CRCTU), Institute of Cancer and Genomic Sciences, \\ University of Birmingham, Birmingham B15 2TT, UK; b.kadir@bham.ac.uk \\ 3 Surgical Reconstruction and Microbiology Research Centre, National Institute for Health Research, \\ Queen Elizabeth Hospital, Birmingham B15 2TH, UK \\ 4 Centre for Trauma Sciences Research, University of Birmingham, Edgbaston, Birmingham B15 2TT, UK \\ * Correspondence: z.ahmed.1@bham.ac.uk
}

Citation: Chan, C.N.; Kadir, B.; Ahmed, Z. The Role of Prehospital REBOA for Hemorrhage Control in Civilian and Military Austere Settings: A Systematic Review. Trauma Care 2022, 2, 63-78. https:/ / doi.org/10.3390/traumacare2010006

Received: 9 November 2021

Accepted: 21 February 2022

Published: 25 February 2022

Publisher's Note: MDPI stays neutral with regard to jurisdictional claims in published maps and institutional affiliations.

Copyright: (C) 2022 by the authors. Licensee MDPI, Basel, Switzerland. This article is an open access article distributed under the terms and conditions of the Creative Commons Attribution (CC BY) license (https:// creativecommons.org/licenses/by/ $4.0 /)$.

\begin{abstract}
Despite the success of prehospital resuscitative endovascular balloon occlusion of the aorta (REBOA) in combat and civilian settings, the prevalence of complications and the lack of conclusive evidence has led to uncertainty and controversy. Therefore, this systematic review aimed to evaluate the role of prehospital REBOA for hemorrhage control in trauma populations. We systematically searched Cochrane, Ovid MEDLINE, EMBASE and Google Scholar for all relevant studies that investigated the efficacy of prehospital REBOA on trauma patients with massive hemorrhage. Primary outcome was evaluated by blood pressure elevation and secondary outcome was measured by 30-day mortality and complications. Our search identified 546 studies, but only six studies met the inclusion and exclusion criteria. Included studies were low to moderate quality due to limitations within the studies. However, all of the studies reported significant elevation of blood pressure and survival, demonstrating the potential benefits of REBOA. For example, the 30-day mortality rate reduced significantly after REBOA, but studies lacked long-term outcome assessments across the continuum of care. Due to the heterogeneity of the results, a meta-analysis was not possible. We conclude that prehospital REBOA is a feasible and effective resuscitative adjunct for shock patients with lethal non-compressible torso hemorrhage. However, due to the unclear causes of complications and the lack of high quality and homogeneous data, the effects of prehospital REBOA were not truly reflected and comparison between groups was not feasible. Thus, further high-quality studies are required to attest the causality between prehospital REBOA and outcomes.
\end{abstract}

Keywords: prehospital; REBOA; aortic occlusion; hemorrhage; trauma

\section{Introduction}

Traumatic hemorrhage is a global problem that accounts for up to $40 \%$ of trauma mortality, owing to violence, road traffic accidents and military conflicts [1-3]. More than one-fourth of these deaths were preventable, occurring before arrival at hospitals or definitive care. In both civilian and military settings, non-compressible torso hemorrhage (NCTH) represented the largest proportion of mortalities [1-4]. A large-scale study of the US Trauma registry postulated that the increase in prehospital time or the torso injury severity results in significantly higher mortality, where the first peak of death was identified in the first $30 \mathrm{~min}$ after significant torso trauma [2]. However, evacuation within the first $30 \mathrm{~min}$ is often infeasible or even unrealistic in austere settings. Despite the advent of novel hemostatic devices, NCTH are neither amenable to them nor to direct pressure. Therefore, efficient early proximal hemorrhage controls are imperative to temporize lethal conditions and to bridge patients to definitive care. 
Due to the poor results of using resuscitative thoracotomy (RT) for aortic occlusion [5], resuscitative endovascular balloon occlusion of the aorta (REBOA) has been proposed to act instead in the setting of NCTH, since existing evidence suggests it significantly improves the overall survival rate $(16.7 \%$ vs. $62.5 \%, p<0.001)[5,6]$. REBOA is a minimally invasive method that involves percutaneous insertion of a balloon catheter into the femoral artery and occlusion of the descending thoracic aorta (Zone I) or distal abdominal aorta (Zone III), depending on the indication. This aims to temporarily arrest the arterial inflow, restore circulating blood volume and preserve brain perfusion for patients with severe exsanguination [7]. The concept of aortic occlusion was first introduced in the Korean War by Carl Hughes despite its failure [8]. However, with advanced technology, the REBOA catheter has now emerged onto a variety of clinical scenarios, for instance, ruptured abdominal aortic aneurysm and post-partum hemorrhage and gastrointestinal tract bleeding [9-12] The outcomes were found encouraging for both trauma and non-trauma patients in civilian and military settings, where it is also currently incorporated in the Joint Trauma System Clinical Practice [13]. This could be very beneficial to numerous military patients, as a surge in casualties sustaining NTCH has been underscored by the US Department of Defense, owing to increased improvised explosive device use [13-15].

Nonetheless, REBOA has potential devastating complications due to ischemic effects secondary to occlusion, for example, limb amputations, arterial dissection and balloonrelated thromboembolic events [7]. A propensity score and sensitivity analysis on a large Japanese trauma population reported that the in-hospital mortality was significantly higher in the REBOA group than the non-REBOA group (61.8\% vs. $45.3 \%$ ) [16]. This could result from delayed definite hemostasis due to limited surgical capability, as the median door-toprimary surgery time was $97 \mathrm{~min}$ [17]. This revealed its time-dependent feature, requiring meticulous consideration about the risk and benefits based on available resources.

In the prehospital aspect, there is a paucity of inclusive data analysis about the best evidence-based practice of REBOA. Some statements and explanations of existing protocols are not clearly defined, and thus a systematic review on the effectiveness of prehospital REBOA use in traumatic hemorrhage has been attempted. This may help answer the questions of this literature gap by outlining conclusive evidence and providing a reliable basis for protocol enhancement to achieve the optimal clinical outcomes.

\section{Materials and Methods}

\subsection{Literature Search}

The search and reporting of this review adhere to the protocols recommended by the Preferred Reporting Items for Systematic Reviews and Meta-Analysis statement (PRISMA), the Cochrane Handbook for Systematic Reviews of Interventions and the Joanna Briggs Institute (JBI) Manual for Evidence Synthesis to enhance comprehensiveness and accuracy of this study [18-20]. After scoping searches, four electronic databases (Cochrane Library, Ovid MEDLINE, EMBASE, Google Scholar) were searched for relevant literatures from the inception to June 2021. The PICO strategy (Table 1) was adopted to identify the following keywords: "hemorrhage", "trauma", "prehospital", "REBOA", "resuscitative endovascular balloon occlusion of the aorta", "aortic occlusion" and "balloon occlusion". These terms were searched with different combinations in the title and abstract and against the exclusion criteria. Furthermore, the reference lists of all the literatures were also examined with the aim of being as inclusive as possible.

Table 1. PICO of the study.

\begin{tabular}{cr}
\hline Patient & Adults with traumatic haemorrhage \\
\hline Intervention & Standard prehospital resuscitative interventions with REBOA \\
\hline Comparison & Standard prehospital resuscitative interventions without REBOA \\
\hline Outcome & Improved hemodynamic and reduced mortality \\
\hline
\end{tabular}




\subsection{Data Collection}

Two researchers (C.N.C. and Z.A.) independently performed the literature search and assessed the titles and abstracts for inclusion eligibility according to the inclusion and exclusion criteria (Table 2). The full texts of potentially eligible literatures were retrieved for further assessments.

Table 2. Inclusion and exclusion criteria.

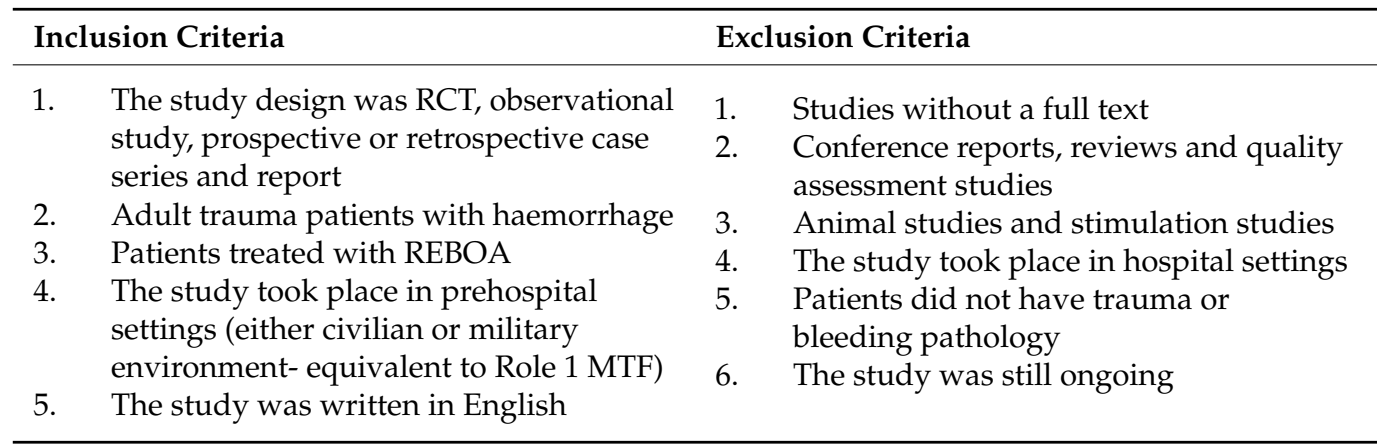

\subsection{Data Extraction and Synthesis}

Relevant data from the included studies were extracted and presented in tables where they were cross-checked and agreed upon by two researchers (C.N.C. and Z.A.). These extracted data were then divided into three parts: study characteristics, population characteristics and study results.

\subsection{Quality Assessment}

As all the studies included were case reports and case series, the JBI Critical Appraisal Tools for Systematic Reviews were used to evaluate the methodological quality of the included studies, in terms of the risk of bias in design, implementation, and analysis [20]. The appraisal checklists of case reports and case series have 8 and 10 questions, respectively. They focus on similar domains and allow responses with "Yes" for a low risk of bias, "No" for a high risk of bias and "Unclear" for an unclear risk of bias. Two reviewers (C.N.C. and Z.A.) assessed each article independently with the JBI tools and disagreement was solved through discussion.

\subsection{Statistical Analysis}

The included studies in this review were all retrospective descriptive studies where the clinical data (interventions, inclusion and exclusion criteria, outcome measurements), methodology (quality) and statistical significance were heterogeneous. These limited the eligibility of combination and integration of the extracted data. The available data was also analyzed by a medical statistician (B.K.), who agreed that there was a lack of statistical homogeneity for meta-analysis. Therefore, only a narrative synthesis could be carried out.

\section{Results}

\subsection{Study Selection}

A total of 546 articles were identified in Cochrane Library, Ovid MEDLINE, EMBASE and Google Scholar. After de-duplication, 533 studies were left for screening. Their titles and abstracts were examined for eligibility and were marked as 1, 2, 3, 4 and 5, which represented irrelevant studies, prehospital REBOA on animals, in-hospital REBOA on humans, prehospital REBOA on cadaver models and prehospital REBOA on humans, respectively. Seven potential studies were retained [21-27] and full text assessments were conducted. One study [27] was excluded because it was conducted in Role 2 MTF, where 'prehospital care' is defined as the medical care from the point of injury to Role 1 military Medical Treatment Facility (MTF), according to the North Atlantic Treaty Organization 
Doctrine [28]. As a result, six articles were included in this systematic review. The PRISMA flow diagram is shown in Figure 1.

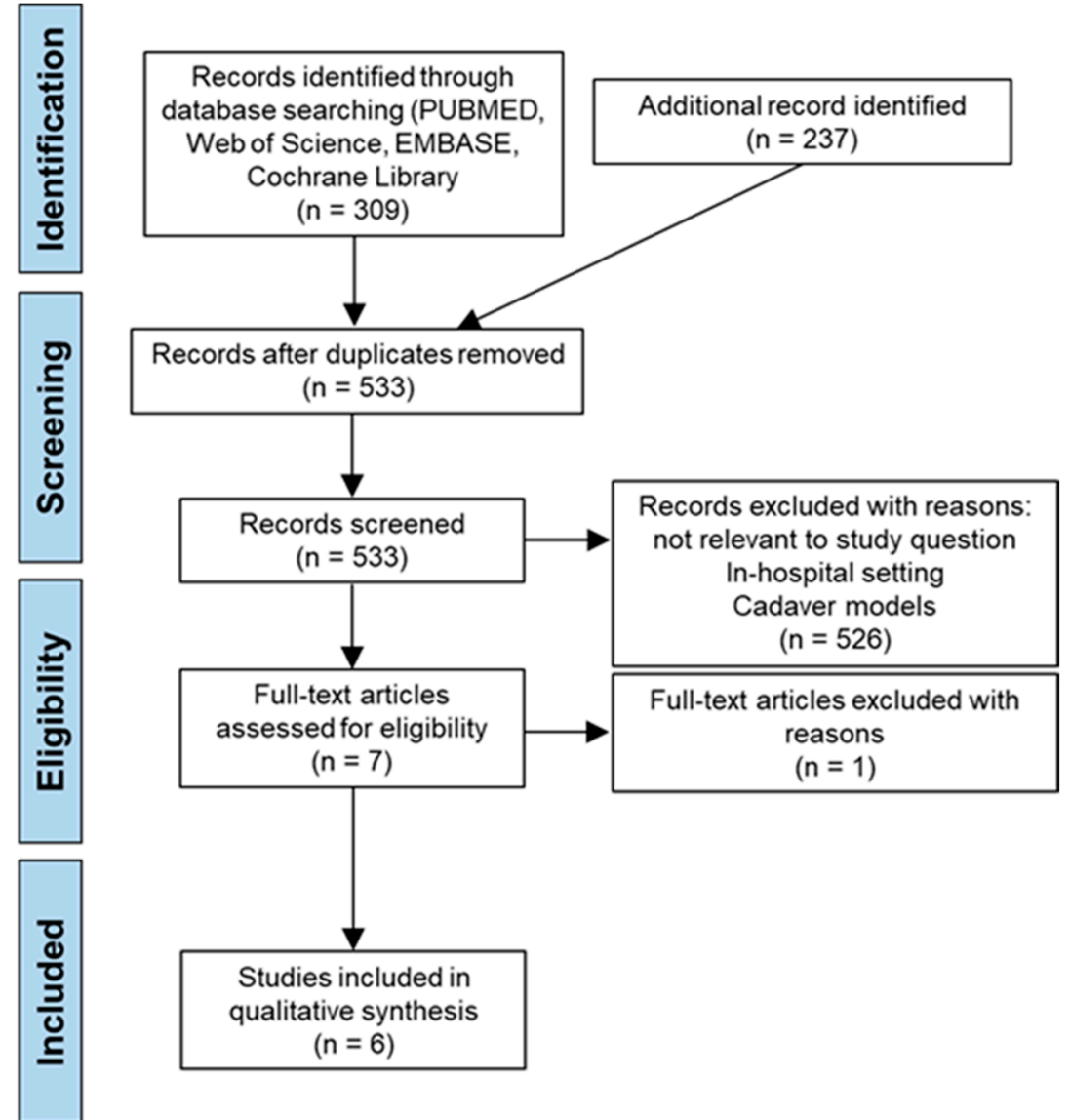

Figure 1. PRISMA flow diagram.

\subsection{Study Characteristics}

All six included studies were retrospective and descriptive in nature and were carried out in different western countries (the United Kingdom, the United States, France and Belgium) and published between 2016 and 2019 (Table 3). Three studies were conducted in civilian settings, while the other three were carried out in a far-forward unit of military medical care. Only three studies [21,25,26] clearly depicted inclusion criteria for REBOA utilization while the other three [22-24] did not. They shared comparable patient inclusion criteria, including non-compressible hemorrhage, blunt and penetrating injuries and shock $(\mathrm{SBP}<90 \mathrm{mmHg})$. 
Table 3. Characteristics of the included studies in chronological order.

\begin{tabular}{|c|c|c|c|c|c|c|c|}
\hline Study & Design & Country & Setting & $\begin{array}{l}\text { Inclusion and } \\
\text { Exclusion Criteria }\end{array}$ & $\begin{array}{l}\text { Intervention Protocol } \\
\text { (Prehospital) }\end{array}$ & Outcomes Measures & $\begin{array}{l}\text { Study } \\
\text { Quality }\end{array}$ \\
\hline Sadek et al., 2016 [21] & $\begin{array}{l}\text { Case } \\
\text { report }\end{array}$ & UK & Civilian & 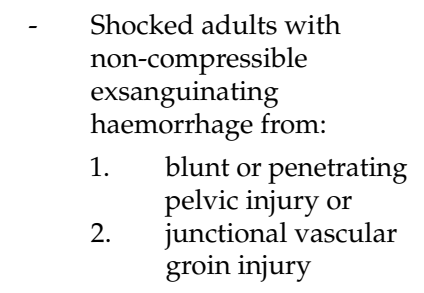 & $\begin{array}{ll}\text { - } & \text { REBOA only deployed in } \\
\text { - } & \text { Zone Three } \\
\text { - } & \text { Blood transfusion } \\
& \text { intubation } \\
- & \text { Anaesthesia } \\
- & 14 \mathrm{~mm} 7 \text { Fr embolectomy } \\
& \text { balloon catheter }\end{array}$ & $\begin{array}{ll}- & \text { Blood pressure } \\
- & \text { Blood gas analysis } \\
- & \text { Blood product } \\
& \text { consumption } \\
- & \text { Length of ICU stay } \\
\text { - } & \text { Survival to discharge }\end{array}$ & Low \\
\hline Manley et al., 2017 [22] & $\begin{array}{l}\text { Case } \\
\text { series }\end{array}$ & $\begin{array}{l}\text { FST operated by the } \\
\text { US SOST }\end{array}$ & Military & Not specified & $\begin{array}{ll}\text { - } & \text { Whole blood transfusion } \\
- & \text { Antibiotics } \\
- & 1 \mathrm{~g} \text { tranexamic acid } \\
- & \text { FAST examination } \\
\text { - } & \text { with Vscan } \\
& 7 \text { Frytime ER-REBOA }\end{array}$ & $\begin{array}{ll}\text { - } & \text { Blood pressure } \\
\text { - } & \text { Survival to 2-h transfer to } \\
\text { the next level of care } \\
\text { - } \\
\text { REBOA-related } \\
\text { complications }\end{array}$ & Moderate \\
\hline Northern et al., 2018 [23] & $\begin{array}{l}\text { Case } \\
\text { series }\end{array}$ & $\begin{array}{l}\text { FST operated by the } \\
\text { US SOST }\end{array}$ & Military & Not specified & $\begin{array}{ll}\text { - } & \text { FAST exam for abdominal } \\
\text { and chest evaluation } \\
\text { - } & \text { Whole blood resuscitation } \\
\text { - } & 7 \text { Fr Prytime ER-REBOA }\end{array}$ & $\begin{array}{ll}\text { - } & \text { Blood pressure } \\
\text { - } & \text { REBOA access site } \\
\text { - } & \text { complications } \\
\text { Survival to the next level } \\
\text { of care }\end{array}$ & Moderate \\
\hline Lamhaut et al., 2018 [24] & $\begin{array}{l}\text { Case } \\
\text { report }\end{array}$ & France & Civilian & Not specified & $\begin{array}{ll}- & \text { Intubation } \\
- & \text { IV fluid } \\
- & \text { Epinephrine } \\
- & 7 \text { Fr Prytime Medical, } \\
& \text { Boerne, TX, USA }\end{array}$ & $\begin{array}{ll}\text { - } & \text { Return to circulation (no } \\
\text { objective data) } \\
\text { - } & \text { Survival to damage } \\
\text { control surgery }\end{array}$ & Low \\
\hline
\end{tabular}


Table 3. Cont.

\begin{tabular}{|c|c|c|c|c|c|c|c|}
\hline Study & Design & Country & Setting & $\begin{array}{l}\text { Inclusion and Exclusion } \\
\text { Criteria }\end{array}$ & $\begin{array}{l}\text { Intervention Protocol } \\
\text { (Prehospital) }\end{array}$ & Outcomes Measures & $\begin{array}{l}\text { Study } \\
\text { Quality }\end{array}$ \\
\hline de Schoutheete et al., 2018 [25] & $\begin{array}{l}\text { Case } \\
\text { series }\end{array}$ & $\begin{array}{l}\text { FCCP operated by the } \\
\text { Belgian SOST }\end{array}$ & Military & $\begin{array}{l}\text { Based on the MIST acronym: } \\
\text { - } \quad \text { Mechanism of injury: } \\
\text { high-energy trauma, } \\
\text { penetrating trauma } \\
\text { Injury: exclude any } \\
\text { bleeding injury above the } \\
\text { diaphragm (e.g., cardiac } \\
\text { tamponade and } \\
\text { tension pneumothorax) } \\
\text { Signs: shock, } \\
\text { SBP }<90 \mathrm{mmHg}\end{array}$ & $\begin{array}{ll}\text { - } & \text { FAST examination } \\
\text { - } & \text { IV fluid } \\
\text { - } & \text { Blood transfusion } \\
\text { - } & \text { Tranexamic acid } \\
\text { - } & \text { Antibiotics } \\
\text { - } & \text { Vasopressor } \\
\text { - } & \text { pREBOA strategy } \\
\text { - } & \text { 7Fr ER-REBOA }\end{array}$ & $\begin{array}{ll}\text { - } & \text { Blood pressure } \\
\text { - } & \text { Survival to definite care } \\
\text { - } & \text { Complications } \\
\text { - } & \text { Blood product } \\
& \text { consumption }\end{array}$ & Moderate \\
\hline Lendrum et al., 2019 [26] & $\begin{array}{l}\text { Case } \\
\text { series }\end{array}$ & UK & Civilian & $\begin{array}{l}\text { Non-compressible } \\
\text { exsanguinating } \\
\text { haemorrhage from blunt } \\
\text { or penetrating } \\
\text { pelvic injury } \\
\text { Imminent hypovolemic } \\
\text { cardiac arrest }\end{array}$ & $\begin{array}{ll}\text { - } & \text { Zone Three occlusion only } \\
\text { - Standard trauma care } \\
\text { protocol: Direct pressure, } \\
\text { immobilisation of } \\
\text { fractured site, intravenous } \\
\text { access, Tranexamic acid, } \\
\text { red cell transfusion } \\
\text { - No surgical cutdown } \\
\text { for CFA } \\
\text { - Maximum 8Fr sheath }\end{array}$ & $\begin{array}{ll}\text { - } & \text { Blood pressure } \\
\text { - } & \text { Prehospital hypovolemic } \\
\text { cardiac arrest } \\
\text { - } & \text { Lower limb amputation } \\
\text { - } & \text { Procedural complications } \\
\text { - } & \text { Survival to } \\
& \text { hospital discharge }\end{array}$ & Moderate \\
\hline
\end{tabular}

Notes: FST, a far-forward surgical unit; SOST, Air Force Special Operations Surgical Teams; FCCP, far-forward casualty collection point; CFA, common femoral artery; Vscan, a handheld

Ultrasound; pREBOA, a gradual deflation of the balloon after confirmation of hemodynamic stabilization and aims to keep systolic blood pressure >90 mmHg [25]. 
Moreover, the intervention protocols among six studies were diverse and were not clearly described. Four studies encompassed blood products use but they did not mention the types and the transfused volume [21-23,25,26]. Five studies mentioned medication uses, such as antibiotics, tranexamic acid and vasopressors without clear records of the dosage and the route of administration [21,22,24-26]. Regarding outcome measurements, most studies only evaluated the short-term efficacy of REBOA due to rapid evacuation and loss of follow-up, particularly in military settings. Primary outcomes were presented with blood pressure change and survival to the next MTF while secondary outcomes were measured by the incidence of complications, given that only two studies managed to measure long-term survival [21,26].

\subsection{Risk of Bias}

As the search was conducted using four English databases, publication and language bias were inherent. Using JBI appraisal tools for the scrutiny, the quality of included studies was determined to be low to moderate (Figures 2 and 3). Two case reports poorly presented cases as a timeline and lacked patients' clinical details, such as history, preand post-intervention conditions and complications [21,24]. For the case series, although they demonstrated a comparatively higher quality, half of them obscurely describe the inclusion criteria, patients' demographics and study site information, affecting the comparability. Paramount essential data were missing, namely, incomplete reporting of long-term outcomes due to the loss to follow up, resulting in bias in outcome measurements and information bias. Owing to the retrospective and descriptive nature, reporting bias, selection bias and allocation bias, bias due to confounding factors was inherent. The heterogeneity existed due to different study contexts and intervention protocols that could greatly influence outcomes and submerge the true effectiveness of prehospital REBOA. Nonetheless, since the procedure is rarely used, this review already encompassed the studies capturing the majority of the cases worldwide, regardless of the absence of high-quality evidence.

Additionally, two studies contained unmatched information in texts and graphs and corresponding authors were contacted for clarification [22,23]. However, there was no response received, which may subsequently affect the reliability of this review.

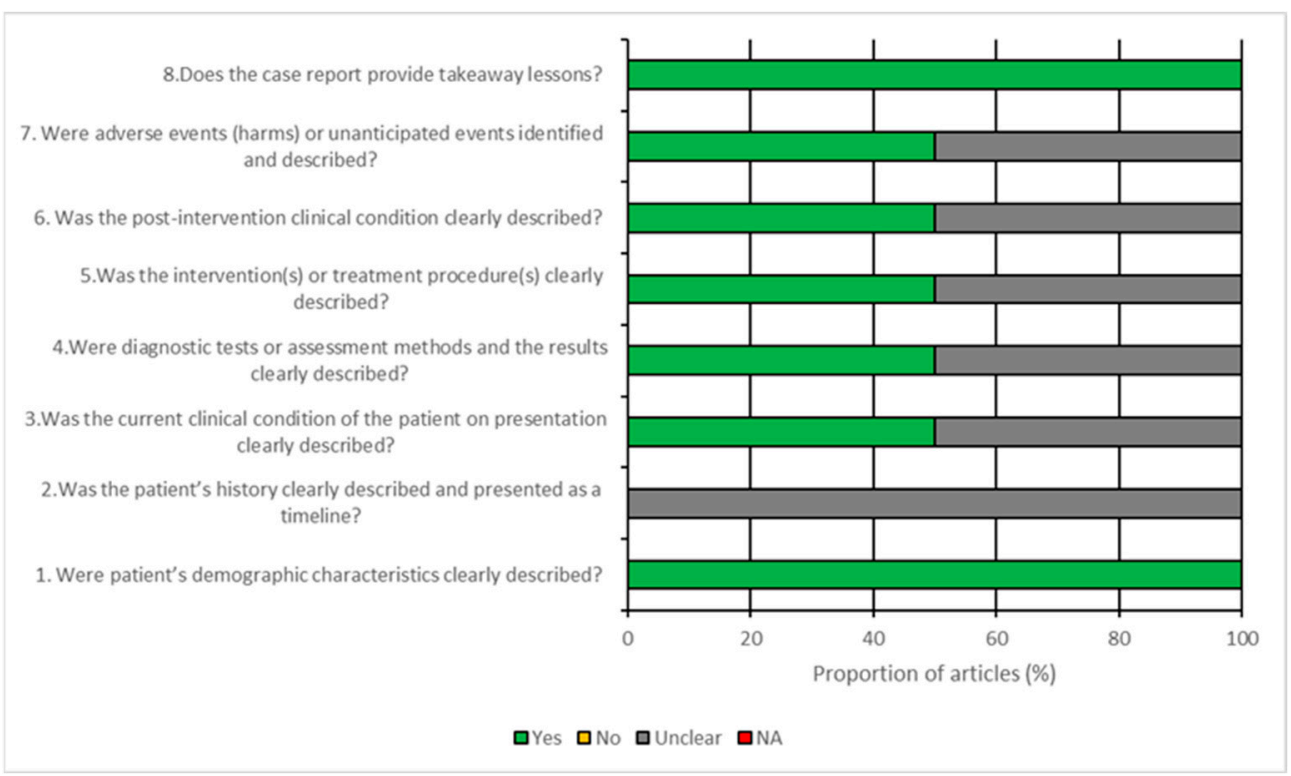

Figure 2. Quality assessment of 2 included case reports [21,24]. 


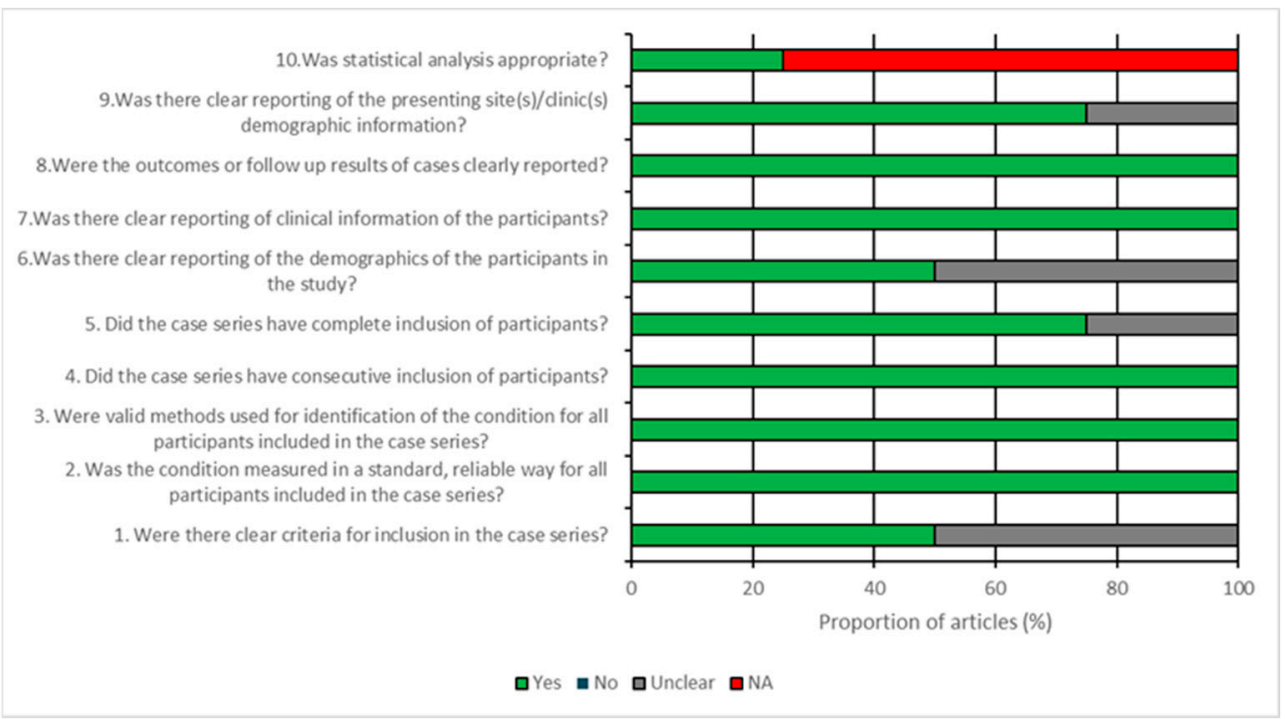

Figure 3. Quality assessment of 4 included case series studies $[22,23,25,26]$.

\subsection{Patient Characteristics}

The patient characteristics of included studies were summarized in Table 4 and generally they had small sample sizes, ranging from 1 to 21 patients. Despite the great diversity, all patients sustained severe NCTH with shock or cardiac arrest. For military studies, patients were predominantly male combatants with a narrower age range (18-54 years old), while civilian studies included a wider age range of patients (22-79 years old). The studies used different tools to indicate injury severity, including Injury Severity Score (ISS) and Glasgow Coma Score (GCS). They suggested that most patients sustained a major and severe trauma with ISS $>15$ or GCS $\leq 8$ [29]. Nevertheless, two studies [22,24] did not objectively present the patients' conditions. Regarding injury mechanism, high-energy trauma over torso and pelvic areas were predominant in these patients, regardless of the settings. Military cases were likely to be associated with penetrating gunshots and explosive devices, while civilian cases tended to involve fall and blunt trauma resulting from road traffic accidents.

\subsection{Main Findings}

In the summary of included studies (Table 5), 85\% of the military patients received zone 1 REBOA while 93\% civilian patients had zone 3 REBOA. Most of the studies allowed either percutaneous arterial access or surgical cutdown with a $100 \%$ success rate of catheter placement, while only a $68 \%$ success rate was reported in Lendrum's study due to forbidden cutdown [26]. 
Table 4. Patients' characteristics of included studies.

\begin{tabular}{|c|c|c|c|c|c|c|c|c|}
\hline Study & Sample Size & $\begin{array}{l}\text { Mean Age } \\
\text { (Years) }\end{array}$ & Gender & $\begin{array}{l}\text { Specific } \\
\text { Characteristics } \\
\text { of Interest }\end{array}$ & Injury Severity & $\begin{array}{l}\text { Shock/ } \\
\text { Cardiac Arrest * }\end{array}$ & $\begin{array}{l}\text { Mechanism of } \\
\text { Injury/Injury Patterns }\end{array}$ & $\begin{array}{l}\text { Initial SBP, Mean } \\
\text { (Range) }\end{array}$ \\
\hline Sadek et al. [21] & 1 & 32 & Male & N/A & ISS: 45 & Profound shock & $\begin{array}{l}\text { Fell } 15 \mathrm{~m} \text {; pelvic } \\
\text { haemorrhage }\end{array}$ & Not recordable \\
\hline Manley et al. [22] & 4 & $\begin{array}{l}\text { Not- } \\
\text { mentioned }\end{array}$ & Male & Combat-related & Not mentioned & Shock & $\begin{array}{l}\text { Significant NCTH } \\
\text { penetrating injuries } \\
\text { Gunshot wounds } \\
\text { Diffuse fragmentation }\end{array}$ & $78 \mathrm{mmHg}(70-90 \mathrm{mmHg})$ \\
\hline Northern et al. [23] & $\begin{array}{l}20 \\
\text { (19 successful } \\
\text { AO, } 1 \text { failed })\end{array}$ & $18-30$ & Primarily male & Combatants & GCS: 7-15 & Shock & $\begin{array}{l}\text { NCTH } \\
\text { Gunshot wounds } \\
\text { Explosion injuries }\end{array}$ & $\begin{array}{l}71 \mathrm{mmHg} \\
(50-90 \mathrm{mmHg})\end{array}$ \\
\hline Lamhaut et al. [24] & 1 & 49 & Female & $\begin{array}{l}\text { Diagnosed with } \\
\text { advanced metastatic } \\
\text { cancer in DCS }\end{array}$ & $\begin{array}{l}\text { Not mentioned but } \\
\text { patient had cardiac arrest } \\
\text { at the scene; GCS should } \\
\text { be } 3\end{array}$ & Cardiac arrest & $\begin{array}{l}\text { Fall from } 30 \text { feet } \\
\text { Blunt trauma with } \\
\text { abdominal torso } \\
\text { haemorrhage }\end{array}$ & Cardiac arrest \\
\hline de Schoutheete et al. [25] & 3 & $40(25-54)$ & $\begin{array}{l}2 \text { Male, } \\
1 \text { female }\end{array}$ & $\begin{array}{l}\text { No known } \\
\text { peripheral vascular } \\
\text { disease. }\end{array}$ & Mean ISS:36 (20-66) & $\begin{array}{l}1 \text { Shock, } \\
2 \text { Cardiac arrest }\end{array}$ & $\begin{array}{l}\text { High-velocity } \\
\text { penetrating trauma due } \\
\text { to IEDs or gunshots }\end{array}$ & $\begin{array}{l}2 \text { patients: } \\
\text { non-measurable } \\
1 \text { patient: } 60 \mathrm{mmHg}\end{array}$ \\
\hline Lendrum et al. [26] & $\begin{array}{l}21 \\
\text { (19 trauma } \\
\text { patients) }\end{array}$ & $22-79$ & $\begin{array}{l}10 \text { female, } \\
9 \text { male }\end{array}$ & $\mathrm{N} / \mathrm{A}$ & $\begin{array}{l}\text { Median ISS 34, } \\
\text { IQR: } 27-43\end{array}$ & Profound shock & $\begin{array}{l}\text { High-energy } \\
\text { blunt trauma, } \\
\text { pelvic haemorrhage due } \\
\text { to fall, RTC }\end{array}$ & $\begin{array}{l}\text { Median SBP: } 57 \mathrm{mmHg} \\
\text { (IQR: } 40-68 \mathrm{mmHg} \text { ) }\end{array}$ \\
\hline
\end{tabular}

Notes: * Systolic blood pressure (SBP) less than $90 \mathrm{mmHg}$ is defined as shock in this review; N/A, not applicable; NCTH, non-compressible torso haemorrhage. 
Table 5. Summary of main findings of included studies.

\begin{tabular}{|c|c|c|c|c|c|c|c|}
\hline \multirow[t]{2}{*}{ Study } & \multirow[t]{2}{*}{$\begin{array}{l}\text { Zone of Balloon } \\
\text { Deployment }\end{array}$} & \multirow[t]{2}{*}{$\begin{array}{l}\text { Success Rate in Catheter } \\
\text { Placement }\end{array}$} & \multirow[t]{2}{*}{$\begin{array}{l}\text { Time of Occlusion } \\
\text { (Mean) }\end{array}$} & \multirow[t]{2}{*}{$\begin{array}{l}\text { Primary Outcomes } \\
\text { (Change in BP) }\end{array}$} & \multicolumn{3}{|l|}{ Secondary Outcomes } \\
\hline & & & & & $\begin{array}{l}\text { Survival to the } \\
\text { Next Higher Level } \\
\text { of MTF }\end{array}$ & 30 day Mortality Rate & Complications \\
\hline Manley et al. [22] & $\begin{array}{l}\text { Zone One } \\
(\mathrm{n}=3) \\
\text { Zone } 3 \\
(\mathrm{n}=1)\end{array}$ & $\begin{array}{l}100 \% \\
\text { (Femoral arterial access- } 3 \\
\text { percutaneous, } 1 \text { cutdown) }\end{array}$ & $\begin{array}{l}\text { Zone One: } 25 \mathrm{~min} \\
\text { Zone Three: } 65 \mathrm{~min}\end{array}$ & $\begin{array}{l}51 \% \\
\text { (Mean SBP } 78 \text { mmHg } \\
->118 \mathrm{mmHg} \text { ) }\end{array}$ & $100 \%$ & $\mathrm{~N} / \mathrm{A}$ & $\begin{array}{l}\text { No access-related site } \\
\text { complication in open } \\
\text { cut-down patients } \\
\text { One patient had femoral sheath } \\
\text { hematoma, exploration and } \\
\text { arteriotomy repair } \\
\text { done uneventfully } \\
\text { One patient had distal migration } \\
\text { of the balloon }\end{array}$ \\
\hline Northern et al. [23] & $\begin{array}{l}\text { Zone One } \\
(\mathrm{n}=17) \\
\text { Zone } 3 \\
(n=3)^{*}\end{array}$ & $\begin{array}{l}100 \% \\
\text { (Femoral arterial access } 13 \\
\text { percutaneous, } 6 \text { cut down) }\end{array}$ & $\begin{array}{l}\text { Zone One: } 21 \mathrm{~min} * \\
\text { Zone Three: } 9 \mathrm{~min}\end{array}$ & $\begin{array}{l}79 \% \text {; } \\
\text { (Mean SBP } 71 \mathrm{mmHg} \\
->127 \mathrm{mmHg} \text { ) }\end{array}$ & $100 \%$ & N/A & $\begin{array}{l}\text { No access-related } \\
\text { site complication } \\
\text { One patient had failed zone } 3 \\
\text { REBOA with no pressure change, } \\
\text { suspected balloon rupture due to } \\
\text { overinflation, Shunting and } \\
\text { ligation were done uneventfully } \\
\text { to temporise the wound }\end{array}$ \\
\hline de Schoutheete et al. [25] & $\begin{array}{l}\text { Zone One } \\
(n=3)\end{array}$ & $\begin{array}{l}100 \% \\
\text { (1 percutaneous, } 2 \text { cutdown) }\end{array}$ & Zone One: $31 \mathrm{~min}$ & $\begin{array}{l}\text { Non-measurable \& } \\
\text { cardiac arrest \& } \\
\text { SBP } 60 \\
->\text { Mean SBP: } 77 \mathrm{mmHg} \\
(70-90 \mathrm{mmHg})\end{array}$ & $100 \%$ & N/A & $\begin{array}{l}\text { Two patients } \\
\text { developed thrombosis } \\
\text { (One before surgical closure } \\
\text { without clear cause, one after due } \\
\text { to a technical error) }\end{array}$ \\
\hline Lendrum et al. [26] & $\begin{array}{l}\text { Zone Three } \\
(n=13)\end{array}$ & $\begin{array}{l}68 \% \\
6 / 19 \text { failed attempts in trauma } \\
\text { patients due to inability to obtain } \\
\text { arterial access resulting from poor } \\
\text { US visualisation of CFA or failure } \\
\text { to pass a guidewire) }\end{array}$ & $\begin{array}{l}\text { Zone Three: } \\
80 \text { min median } \\
\text { (IQR 75-115). }\end{array}$ & $\begin{array}{l}100 \% \\
\text { (SBP } 57 \mathrm{mmHg}->114 \mathrm{mmHg} \\
\text { (Median of differences } 66, \\
\text { 95\% CI: } 25-74 \\
\text { mmHg; } p<0.001 \text { )) }\end{array}$ & $100 \%$ & $\begin{array}{l}38 \% \\
\text { (Non-REBOA: } 67 \%, p= \\
0.035)\end{array}$ & $\begin{array}{l}77 \%(10 / 13) \text { patients developed } \\
\text { distal arterial thrombus, requiring } \\
\text { embolectomy or thrombectomy, } \\
\text { (6/10 were directly related to a } \\
\text { traumatic vascular injury) } \\
\text { Lower limb amputation: REBOA } \\
\text { group } 31 \% \text {, non REBOA } \\
50 \%, p=0.617 \text { ) }\end{array}$ \\
\hline
\end{tabular}

Notes: * Two patients had complete and partial occlusion in Zone One for $18+8$ min and $30+5$ min, respectively [3]; SBP, systolic blood pressure. 
In these studies, the average occlusion time for zone 1 REBOA was $21 \mathrm{~min}$ to $36 \mathrm{~min}$, which is generally shorter compared to the zone 3 REBOA time of $9 \mathrm{~min}$ to $80 \mathrm{~min}$. All patients in this review demonstrated positive effects of REBOA, showing a significant increase in blood pressure ( $>51 \%)$, except in the study by Lamhaut et al. [24] due to unavailable data. Despite the lack of objective data, the patient returning to spontaneous circulation after REBOA could still be seen as proof of a positive effect. All the patients managed to survive the transport to definite care; however, the secondary outcome measurements such as 30-day mortality were only available in two civilian studies. Their results suggested that prehospital REBOA groups were more likely to survive, with considerably lower 30 -day mortality compared to non-REBOA group (38\% vs. $67 \%$ ) $[21,26]$. The incidence of prehospital cardiac arrest and bleeding-related mortality was also significantly lower in prehospital REBOA patients ( $50 \%$ vs. $0 \%, p=0.031)(67 \%$ vs. $0 \%, p=0.007)$ [26].

Moreover, post-REBOA complications were common in the included patients: thromboembolic events were predominant and reached as high as 77\% among REBOA patients, who required thrombectomy [26].

\subsection{Narrative Synthesis}

A total of 48 patients were enrolled in this review; they all sustained profound shock or cardiac arrest after severe blunt and penetrating trauma. Generally, patients who received prehospital REBOA showed a significant increase in blood pressure $(>50 \%)$ and survived the transport to the next MTF without en route cardiac arrest. Despite the secondary outcome measurements such as 30-day mortality only being available in two civilian studies [21,26], the results suggested REBOA patients were more likely to survive, with a lower mortality rate of $38 \%$ compared to that of $67 \%$ for non-REBOA patients [26]. However, this can only elucidate the association between REBOA and immediate blood pressure elevation, and early hemorrhage control and decreased short-term mortality.

Apart from aortic occlusion, other resuscitative interventions were concurrently used for hemostasis. For instance, blood products and tranexamic acid promoted clotting and prevented fibrinolysis. Other resources, such as surgical capacity, rapid evacuation and responsible personnel's competency along the chain of care were also indispensable. Interestingly, it not only temporized lethal hemorrhage, but also treated the bleeding site in some instances. Six patients stopped bleeding spontaneously with prehospital REBOA alone in Lendrum's study [26]. Also, the benefits were magnified in massive casualties, as it extended the survival window to definite care in the absence of other resources.

Nevertheless, thromboembolic events were prevalent among REBOA patients. The causes were not clearly investigated but attributed to blood transfusion, pro-thrombotic medication uses and traumatic vascular injury instead of REBOA itself. A group of emergency and trauma experts suggested that zone 3 REBOA would minimize visceral ischemic effects if prolonged occlusion time ( $>30 \mathrm{~min}$ ) was expected [26]. 93\% of civilian REBOA cases in this review were deployed in zone 3 while $85 \%$ of military patients received zone 1 REBOA. In general, the transport time between the points of care in military settings is longer than in civilian settings. Due to vaguely described protocols and, paradoxically, zone 1 REBOA with longer occlusion time, the effects of occlusion duration on the outcomes between two different zones were not comparable.

Moreover, the results showed that the restriction-of-arterial-access approach could lower the success rate of catheter placement and subsequently lead to higher mortality. Most of the studies allowed either percutaneous arterial access or surgical cutdown, demonstrating $100 \%$ successful balloon catheter placement, whereas Lendrum et al. [26] had only a $68 \%$ success rate due to forbidden cutdown, having a significantly higher 30-day mortality of $67 \%$ [26].

Due to the substantial heterogeneity across included studies and the missing data, the true effects of prehospital REBOA were still unclear. The causality between REBOA and its effectiveness was not illustrated and conclusions cannot be generalized. 


\section{Discussion}

This systematic review evaluated current evidence regarding the effectiveness of prehospital REBOA in traumatic hemorrhage. Of those included studies, they are determined to have low to moderate quality due to profound limitations. They reported primary outcomes of significant blood pressure elevation and survival to the next MTF, concordantly showing the potential benefits of prehospital REBOA to temporize or even stop lethal bleeding [21-26]. They are consistent with another systematic review's results that REBOA can cause an average $50 \mathrm{mmHg}$ blood pressure increase on patients with severe traumatic exsanguination [30]. However, secondary outcome measurements were heterogeneous. Only [26] reported 30-day mortality with statistical significance, while the remaining studies lacked long-term outcome assessment across the continuum of care. Historically, the peak of deaths occurred within the first $6 \mathrm{~h}$ after arrival at hospitals; therefore, survival to hospitals does not equate to survival to discharge [31-33]. Trauma patients are at high risk of trauma-induced coagulopathy and brain injury, leading to rapid deterioration. The concept of golden hour in trauma care should be applied for early initiation of REBOA [2]. Proactive use was proposed because early access was found to be associated with a significantly higher 30-day survival rate, preventing hypovolemic cardiac arrest and facilitating hemodynamic monitoring [16].

REBOA is extraordinarily useful in the context of a mass casualty, as major surgical interventions may not be readily available. Also, proximal aortic occlusion allows a relatively dry field for rapid identification of bleeding sources afterwards [23]. Moreover, it could be a feasible alternative to open thoracotomy for patients requiring aortic cross-clamping with significantly improved overall survival and decreased complication rate, especially in prehospital settings [22,26,34]. Not only useful as a resuscitative adjunct, REBOA could also be therapeutic, since $46 \%$ patients who underwent prehospital REBOA stopped bleeding spontaneously without angio-embolization [26]. This procedure can be achieved by nonspecialist physicians, as advanced endovascular techniques are not compulsory. Training for REBOA skillsets is still necessary for safe and effective implementation.

On the other hand, the outcomes of REBOA could greatly depend on patient selection, resource availability, trauma system integrity and the total balloon occlusion time [21-26]. Although the MIST acronym [25] was used to rapidly identify eligible patients, challenges still exist due to variances among different trauma systems. A customized protocol for an individual system is essential for an efficient procedure. Patient selection requires careful consideration because REBOA may increase the rate of bleeding for patients with contraindications such as cardiac tamponade or bleeding inferior to the balloon. Manley et al. [22] suggested that portable ultrasound machines (V-scan) could offer better diagnostic assessment to exclude patients with contraindications, facilitate REBOA placement and confirm balloon position in a prehospital environment, despite the fact that some studies accomplished the same procedure without its assistance $[21,24,26]$.

Moreover, resource availability and coordination within the trauma system are the keys to success because definitive surgical capability (operating rooms, REBOA operators, etc.) needs to be available expediently followed by REBOA, and blood transfusion is regarded inherent in trauma resuscitation. Three of the included US military studies emphasized the advantages of whole blood transfusion $[22,23,25]$, as advocated by previous military surgeons' experience and incorporated into the 2018 United States Tactical Combat Casualty Care guidelines [35]. In the setting of coagulopathy, the pressure of REBOA alone may be inadequate, so active infusion of blood products and medication uses are necessary to control exsanguination. Whole blood is seen as the optimal balanced resuscitation product with small volume but superior hemostatic effects, compared with balanced component therapy that reconstitutes whole blood with platelets, plasma and red cells [36,37]. The function of reconstituted platelets is reduced and the larger volume could result in dilutional coagulopathy [36]. Nonetheless, whole blood is currently unavailable in many western countries and some studies in this review did not specify the types of blood products they 
used, as they may be limited to component therapy. Without adequate data, comparison between the outcomes of REBOA upon transfusion protocols are infeasible.

Other factors such as rapid evacuation and the competency of involved personnel along the chain of care are essential. If the personnel are competent to handle REBOA, the catheter could be retained during transport to facilitate blood pressure monitoring, keep patients stable and potentially allow straight evacuation to Role 3 MTF; thus, patients can reach definite care faster.

\subsection{Complications}

Despite the positive effects of prehospital REBOA, most studies reported high thrombotic incidence, reaching as high as $77 \%$ where balloon migration and failure due to balloon rupture were also mentioned $[22,23,26]$. This contradicts other authors claiming that no procedural related complication was observed $[38,39]$. The rate of procedural morbidity \& mortality is proposed to be associated with occlusion time and sheath size [38-40]. Prolonged total occlusion time with REBOA strongly correlated with increased lactate concentration $(p=0.02)$ and visceral ischemic injury, particularly for Zone 1 REBOA [41]. To minimize the procedural risk, the included studies adopted small sheath size catheters ( $<8 \mathrm{Fr}$ ) and some of them were restricted to zone 3 REBOA because theoretically zone 1 REBOA had a stricter time limit due to the ischemic effects on more sensitive renal tissues. Paradoxically, $85 \%$ of military cases had zone 1 REBOA with supposing longer evacuation time compared to civilian settings (Table 5).

Moreover, complete balloon deflation at once after prolonged AO may cause washout of metabolic by-products and reperfusion injury. To avoid refractory hemodynamic collapse, a dynamic approach or early partial REBOA (pREBOA) was adopted to allow titrated blood flow to distal tissues $[23,25,26]$. de Schoutheete [25] defined the dynamic approach as using a partial occlusion and manual operating method on the aortic compliance to keep systolic blood pressure not higher than $90 \mathrm{mmHg}$. Small and gradual deflation of balloon and the idea of causing hypotension were introduced to tackle the reperfusion injury [25]. A Japanese multicenter retrospective study showed that pREBOA significantly improved patients' hemodynamics and stability, better than complete REBOA (cREBOA) $(p<0.05)$ [42]. Regardless of significantly longer occlusion in the pREBOA group, it had similar 30-day survival to cREBOA. Therefore, pREBOA may be superior to cREBOA, allowing extended occlusion duration without increased risk.

Nevertheless, most studies did not ascertain the causes of complications and relate lower limb amputations to primary amputation or non-salvageable mangled injuries [26]. After trauma, the pathology of hypercoagulation and coagulopathy with concurrent administration of procoagulant blood products and anti-fibrinolytics interfered with the clotting mechanism, potentially prompting thrombosis [26]. Two included studies [21,24] did not report REBOA-related complications, possibly due to single-case inclusion. Since the baseline characteristics were completely different, the outcomes were not comparable, considering that the patient's age and pre-morbidity could affect physical reserve and the response to trauma.

\subsection{Surgical Cutdown versus Percutaneous Access}

Although there was no comparison between the surgical cutdown or percutaneous access in the included studies to determine their superiority, limited percutaneous insertion was found to prohibit the catheter placement, leading to failure of REBOA and reduced survival rate. Since obtaining arterial access is deemed as the most challenging part in prehospital resuscitation for hypovolemic patients, the success rate of catheter placement has become a concern. The civilian studies limited their protocols to percutaneous arterial cannulation, possibly due to current evidence of several randomized control trials that suggest percutaneous femoral access is less invasive and has more favorable outcomes than the cutdown cohort [43]. Also, it shows significantly fewer wound complications, deep vein thrombosis and reduced length of hospital stay. On the contrary, the included 
studies of this review did not report any access-related complication in the open cutdown population. Supported by other authors, surgical cutdown could rapidly expose the anterior vessel wall and no significant difference was seen in access-related complications between two methods [44,45]. Although a new REBOA catheter allows manual compression after removal, open common femoral artery closure is still recommended in case of uncontrolled exsanguination during unexpected duration of evacuation. The two insertion approaches should be considered complementary to each other and their availability could enhance the success rate of balloon deployment and subsequent survival.

\subsection{Limitations}

The biggest limitation of this review is the lack of high-quality studies, depreciating its generalizability. The mediocre data quality resulted from the retrospective and descriptive nature of included studies. Restrictions in English databases and patient survival caused publication bias, small sample size caused decreased statistical power and loss of long-term follow-up caused reporting bias and missing data. With uncontrolled variables, causality cannot be established and the included evidence cannot show explicit correlation between occlusion time, zone of balloon deployment and outcomes. Thus, it is difficult to clearly define the time limit for balloon occlusion in different regions. Moreover, the success of prehospital REBOA is setting-dependent and involves the entire trauma system and the competence of medical personnel, so it is unfair to compare the outcomes of studies having heterogeneous contexts. Since the medical personnel in this review were recruited in developed countries and were highly trained and adhered to institutional protocol within mature trauma systems, the results may not be transferrable to other developing countries. These limitations affect the detecting power and reliability of this review, as the treatment efficacy could be under or overestimated.

However, these limitations are to be expected because REBOA is rarely used in prehospital settings. This review has already captured the majority of the prehospital REBOA operations performed worldwide; hence, the findings attained can serve as a steppingstone for any future studies. Consistently, studies supported the fact that for patients who arrive at a trauma center, death from hemorrhage occurs within approximately $2 \mathrm{~h}$ of being in the hospital.

\section{Conclusions}

Our study demonstrated that prehospital REBOA is a feasible and effective resuscitative adjunct for shock patients with lethal traumatic NCTH. This could be safely and effectively performed by non-specialist physicians with appropriate REBOA training. However, the quality of evidence presented was low to moderate and thus conclusions from the study should be interpreted with care. Larger, high-quality studies are therefore warranted to improve the evidence base for the use of REBOA in hemorrhage control in the prehospital environment.

Author Contributions: Conceptualization, C.N.C. and Z.A.; methodology, C.N.C. and B.K.; formal analysis, C.N.C. and Z.A.; investigation, C.N.C. and Z.A.; data curation, C.N.C., B.K. and Z.A.; writing—original draft preparation, C.N.C.; writing—review and editing, C.N.C., B.K. and Z.A.; supervision, Z.A.; project administration, C.N.C. All authors have read and agreed to the published version of the manuscript.

Funding: This research received no external funding.

Institutional Review Board Statement: Ethical review and approval were waived for this study as per advice from the NHS Health Research Authority (UK) decision tool, since it is a systematic review of published literature.

Informed Consent Statement: Patient consent was waived because no patients or members of the public were involved in the design, conduct of this study, or reporting of this research.

Data Availability Statement: All data generated as part of this study are included in the article. 
Conflicts of Interest: The authors declare no conflict of interest.

\section{References}

1. Kauvar, D.S.; Lefering, R.P.; Wade, C.E. Impact of Hemorrhage on Trauma Outcome: An Overview of Epidemiology, Clinical Presentations, and Therapeutic Considerations. J. Trauma Acute Care Surg. 2006, 60, S3-S11. [CrossRef]

2. Alarhayem, A.Q.; Myers, J.G.; Dent, D.; Liao, L.; Muir, M.; Mueller, D.; Nicholson, S.; Cestero, R.; Johnson, M.C.; Stewart, R.; et al. Time is the enemy: Mortality in trauma patients with hemorrhage from torso injury occurs long before the "golden hour". Am. J. Surg. 2016, 212, 1101-1105. [CrossRef] [PubMed]

3. Davis, J.S.; Satahoo, S.S.; Butler, F.K.; Dermer, H.; Naranjo, D.; Julien, K.; Van Haren, R.M.; Namias, N.; Blackbourne, L.H.; Schulman, C.I.; et al. An analysis of prehospital deaths: Who can we save? J. Trauma Acute Care Surg. 2014, 77, 213-218. [CrossRef] [PubMed]

4. $\quad$ Eastridge, B.J.; Mabry, R.L.; Seguin, P.; Cantrell, J.; Tops, T.; Uribe, P.; Mallett, O.; Zubko, T.; Oetjen-Gerdes, L.; Rasmussen, T.E.; et al. Death on the battlefield (2001-2011): Implications for the future of combat casualty care. J. Trauma Acute Care Surg. 2012, 73, S431-S437. [CrossRef] [PubMed]

5. Moore, L.J.; Brenner, M.; Kozar, R.A.; Pasley, J.; Wade, C.E.; Baraniuk, M.S.; Scalea, T.; Holcomb, J.B. Implementation of resuscitative endovascular balloon occlusion of the aorta as an alternative to resuscitative thoracotomy for noncompressible truncal hemorrhage. J. Trauma Acute Care Surg. 2015, 79, 523-530. [CrossRef]

6. $\quad$ Manzano Nunez, R.; Naranjo, M.P.; Foianini, E.; Ferrada, P.; Rincon, E.; García-Perdomo, H.A.; Burbano, P.; Herrera, J.P.; García, A.F.; Ordoñez, C.A. A meta-analysis of resuscitative endovascular balloon occlusion of the aorta (REBOA) or open aortic cross-clamping by resuscitative thoracotomy in non-compressible torso hemorrhage patients. World J. Emerg. Surg. 2017, 12, 30. [CrossRef]

7. Brenner, M.; Bulger, E.M.; Perina, D.G.; Henry, S.; Kang, C.S.; Rotondo, M.F.; Chang, M.C.; Weireter, L.J.; Coburn, M.; Winchell, R.J.; et al. Joint statement from the American College of Surgeons Committee on Trauma (ACS COT) and the American College of Emergency Physicians (ACEP) regarding the clinical use of Resuscitative Endovascular Balloon Occlusion of the Aorta (REBOA). Trauma Surg. Acute Care Open. 2018, 3, e000154. [CrossRef]

8. Hughes, C.W. Use of an intra-aortic balloon catheter tamponade for controlling intra-abdominal hemorrhage in man. Surgery 1954, 36, 65-68.

9. Brenner, M.L.; Moore, L.J.; DuBose, J.J.; Tyson, G.H.; McNutt, M.K.; Albarado, R.P.; Holcomb, J.B.; Scalea, T.M.; Rasmussen, T.E. A clinical series of resuscitative endovascular balloon occlusion of the aorta for hemorrhage control and resuscitation. J. Trauma Acute Care Surg. 2013, 75, 506-511. [CrossRef]

10. Sato, R.; Kuriyama, A.; Takaesu, R.; Miyamae, N.; Iwanaga, W.; Tokuda, H.; Umemura, T. Resuscitative endovascular balloon occlusion of the aorta performed by emergency physicians for traumatic hemorrhagic shock: A case series from Japanese emergency rooms. J. Crit. Care 2018, 22, 103. [CrossRef]

11. Kunitatsu, K.; Ueda, K.; Iwasaki, Y.; Yamazoe, S.; Yonemitsu, T.; Kawazoe, Y.; Kawashima, S.; Shibata, N.; Kato, S. Outcomes of abdominal trauma patients with hemorrhagic shock requiring emergency laparotomy: Efficacy of intra-aortic balloon occlusion. Acute Med. Surg. 2016, 3, 345-350. [CrossRef] [PubMed]

12. Borger van der Burg, B.L.S.; van Dongen, T.T.; Morrison, J.J.; Hedeman Joosten, P.P.A.; DuBose, J.J.; Hörer, T.M.; Hoencamp, R. A systematic review and meta-analysis of the use of resuscitative endovascular balloon occlusion of the aorta in the management of major exsanguination. Eur. J. Trauma Emerg. Surg. 2018, 44, 535-550. [CrossRef] [PubMed]

13. Joint Trauma System Clinical Practice Guideline (JTS CPG): Resuscitative Endovascular Balloon Occlusion of the Aorta (REBOA) for Hemorrhagic Shock (CPG ID: 38). San Antonio, TX: Joint Trauma System. 2014. Available online: http:/ / www.usaisr.amedd. army.mil/cpgs/REBOA_\%2006Jul2017CORRECTED.pdf (accessed on 24 August 2021).

14. Stannard, A.; Morrison, J.J.; Scott, D.J.; Ivatury, R.A.; Ross, J.D.; Rasmussen, T.E. The epidemiology of noncompressible torso hemorrhage in the wars in Iraq and Afghanistan. J. Trauma Acute Care Surg. 2013, 74, 830-834. [CrossRef] [PubMed]

15. Eastridge, B.J.; Holcomb, J.B.; Shackelford, S. Outcomes of traumatic hemorrhagic shock and the epidemiology of preventable death from injury. Transfusion 2019, 59, 1423-1428. [CrossRef] [PubMed]

16. Matsumura, Y.; Matsumoto, J.; Kondo, H.; Idoguchi, K.; Ishida, T.; Okada, Y.; Kon, Y.; Oka, K.; Ishida, K.; Toyoda, Y.; et al. Early arterial access for resuscitative endovascular balloon occlusion of the aorta is related to survival outcome in trauma. J. Trauma Acute Care Surg. 2018, 3, 507-511. [CrossRef]

17. Inoue, J.; Shiraishi, A.; Yoshiyuki, A.; Haruta, K.; Matsui, H.; Otomo, Y. Resuscitative endovascular balloon occlusion of the aorta might be dangerous in patients with severe torso trauma: A propensity score analysis. J. Trauma Acute Care Surg. 2016, 80, 559-567. [CrossRef]

18. Page, M.J.; McKenzie, J.E.; Bossuyt, P.M.; Boutron, I.; Hoffmann, T.C.; Mulrow, C.D.; Shamseer, L.; Tetzlaff, J.M.; Akl, E.A.; Brennan, S.E.; et al. The PRISMA 2020 statement: An updated guideline for reporting systematic reviews. Br. Med. J. 2021, 372, n71. [CrossRef]

19. Higgins, J.P.; Thomas, J.; Chandler, J.; Cumpston, M.; Li, T.; Page, M.J.; Welch, V.A. Cochrane Handbook for Systematic Reviews of Interventions version 6.2. In Cochrane Handbook for Systematic Reviews of Interventions; John Wiley \& Sons: New York, NY, USA, 2021. Available online: www.training.cochrane.org/handbook (accessed on 8 June 2021).

20. Aromataris, E.; Munn, Z. JBI Manual for Evidence Synthesis. JBI Evid. Synth. 2020, 18, 2106-2107. [CrossRef]

21. Sadek, S.; Lockey, D.J.; Lendrum, R.A.; Perkins, Z.; Price, J.; Davies, G.E. Resuscitative endovascular balloon occlusion of the aorta (REBOA) in the pre-hospital setting: An additional resuscitation option for uncontrolled catastrophic haemorrhage. Resuscitation 2016, 107, 135-138. [CrossRef] 
22. Manley, J.D.; Mitchell, B.J.; DuBose, J.J.; Rasmussen, T.E. A Modern Case Series of Resuscitative Endovascular Balloon Occlusion of the Aorta (REBOA) in an Out-of-Hospital, Combat Casualty Care Setting. J. Spec. Oper. Med. 2017, 17, 1-8.

23. Northern, D.M.; Manley, J.D.; Lyon, R.; Farber, D.; Mitchell, B.J.; Filak, K.J.; Lundy, J.; DuBose, J.J.; Rasmussen, T.E.; Holcomb, J.B. Recent advances in austere combat surgery: Use of aortic balloon occlusion as well as blood challenges by special operations medical forces in recent combat operations. J. Trauma Acute Care Surg. 2018, 85, S98-S103. [CrossRef]

24. Lamhaut, L.; Qasim, Z.; Hutin, A.; Dagron, C.; Orsini, J.P.; Haegel, A.; Perkins, Z.; Pirracchio, R.; Carli, P. First description of successful use of zone 1 resuscitative endovascular balloon occlusion of the aorta in the prehospital setting. Resuscitation 2018, 133, e1-e2. [CrossRef] [PubMed]

25. De Schoutheete, J.C.; Fourneau, I.; Waroquier, F.; De Cupere, L.; O'Connor, M.; Van Cleynenbreugel, K.; Ceccaldi, J.C.; Nijs, S. Three cases of resuscitative endovascular balloon occlusion of the aorta (REBOA) in austere pre-hospital environment-technical and methodological aspects. World J. Emerg. Surg. 2018, 13, 54. [CrossRef] [PubMed]

26. Lendrum, R.; Perkins, Z.; Chana, M.; Marsden, M.; Davenport, R.; Grier, G.; Sadek, S.; Davies, G. Pre-hospital Resuscitative Endovascular Balloon Occlusion of the Aorta (REBOA) for exsanguinating pelvic haemorrhage. Resuscitation 2019, 135, 6-13. [CrossRef] [PubMed]

27. Reva, V.A.; Petrov, A.N.; Samokhvalov, I.M. First Russian experience with endovascular balloon occlusion of the aorta in a zone of combat operations. Angiol. Vasc. Surg. 2020, 26, 61-75. [CrossRef]

28. UK Ministry of Defence. Allied Joint Doctrine for Medical Support (AJP-4.10). 2015. Available online: https://www.gov.uk/ government/publications/allied-joint-medical-support-doctrine-ajp-410 (accessed on 20 June 2021).

29. Palmer, C. Major trauma and the injury severity score-where should we set the bar? Annu. Proc. Assoc. Adv. Automot. Med. 2007, 51, 13-29.

30. Morrison, J.J.; Galgon, R.E.; Jansen, J.O.; Cannon, J.W.; Rasmussen, T.E.; Eliason, J.L. A systematic review of the use of resuscitative endovascular balloon occlusion of the aorta in the management of hemorrhagic shock. J. Trauma Acute Care Surg. 2016, 80, 327-334. [CrossRef]

31. Lansink, K.W.; Gunning, A.C.; Leenen, L.P. Cause of death and time of death distribution of trauma patients in a Level I trauma centre in the Netherlands. Eur. J. Trauma Emerg. Surg. 2013, 39, 375-383. [CrossRef]

32. Butler, F.K.; Holcomb, J.B.; Schreiber, M.A.; Kotwal, R.S.; Jenkins, D.A.; Champion, H.R.; Bowling, F.; Cap, A.P.; Dubose, J.J.; Dorlac, W.C. Fluid resuscitation for hemorrhagic shock in tactical combat casualty care: TCCC Guide- lines Change 14-01- 2 June 2014. J. Spec. Oper Med. 2014, 14, 13-38.

33. Brenner, M.; Teeter, W.; Hoehn, M.; Pasley, J.; Hu, P.; Yang, S.; Romagnoli, A.; Diaz, J.; Stein, D.; Scalea, T. Use of resuscitative endovascular balloon occlusion of the aorta for proximal aortic control in patients with severe hemorrhage and arrest. JAMA Surg. 2018, 153, 130-135. [CrossRef]

34. Lockey, D.; Crewdson, K.; Davies, G. Traumatic cardiac arrest: Who are the survivors? Ann. Emerg. Med. 2006, 48, 240-244. [CrossRef] [PubMed]

35. Butler, F.K.; Holcomb, J.B.; Shackelford, S.; Barbabella, S.; Bailey, J.A.; Baker, J.B.; Cap, A.P.; Conklin, C.C.; Cunningham, C.W.; Davis, M.; et al. Advanced resuscitative care in tactical combat casualty care: TCCC guidelines change 18-01:14 October 2018. J. Spec. Oper. Med. 2018, 18, 37-55. [PubMed]

36. Cotton, B.A.; Podbielski, J.; Camp, E.; Welch, T.; del Junco, D.; Bai, Y.; Hobbs, R.; Scroggins, J.; Hartwell, B.; Kozar, R.A.; et al. A randomized controlled pilot trial of modified whole blood versus component therapy in severely injured patients requiring large volume transfusions. Ann. Surg. 2013, 258, 527-533. [CrossRef] [PubMed]

37. Armand, R.; Hess, J.R. Treating coagulopathy in trauma patients. Transfus. Med. Rev. 2003, 17, 223-231. [CrossRef]

38. Teeter, W.A.; Matsumoto, J.; Idoguchi, K.; Kon, Y.; Orita, T.; Funabiki, T.; Brenner, M.L.; Matsumura, Y. Smaller introducer sheaths for REBOA may be associated with fewer complications. J. Trauma Acute Care Surg. 2016, 81, 1039-1045. [CrossRef]

39. Taylor, J.R., 3rd; Harvin, J.A.; Martin, C.; Holcomb, J.B.; Moore, L.J. Vascular complications from resuscitative endovascular balloon occlusion of the aorta: Life over limb? J. Trauma Acute Care Surg. 2017, 83, S120-S123. [CrossRef]

40. Martinelli, T.; Thony, F.; Decléty, P.; Sengel, C.; Broux, C.; Tonetti, J.; Payen, J.F.; Ferretti, G. Intra-Aortic Balloon Occlusion to Salvage Patients With Life-Threatening Hemorrhagic Shocks From Pelvic Fractures. J. Trauma Acute Care Surg. 2010, 68, 942-948. [CrossRef]

41. Tsurukiri, J.; Akamine, I.; Sato, T.; Sakurai, M.; Okumura, E.; Moriya, M.; Yamanaka, H.; Ohta, S. Resuscitative endovascular balloon occlusion of the aorta for uncontrolled haemorrahgic shock as an adjunct to haemostatic procedures in the acute care setting. Scand. J. Trauma Resusc. Emerg. Med. 2016, 24, 13. [CrossRef]

42. Matsumura, Y.; Matsumoto, J.; Kondo, H.; Idoguchi, K.; Ishida, T.; Kon, Y.; Tomita, K.; Ishida, K.; Hirose, T.; Umakoshi, K.; et al. Fewer REBOA complications with smaller devices and partial occlusion: Evidence from a multicentre registry in Japan. Emerg. Med. J. 2017, 34, 793-799. [CrossRef]

43. Buck, D.B.; Karthaus, E.G.; Soden, P.A.; Ultee, K.H.; Van Herwaarden, J.A.; Moll, F.L.; Schermerhorn, M.L. Percutaneous versus femoral cutdown access for endovascular aneurysm repair. J. Vasc. Surg. 2015, 62, 16-21. [CrossRef]

44. Mayer, D.; Rancic, Z.; Wilhelm, M.; Genoni, M.; Veith, F.J.; Lachat, M. Improved hybrid technique for vascular access and closure. J. Endovasc. Ther. 2008, 15, 322-325. [CrossRef] [PubMed]

45. Spitzer, S.G.; Wilbring, M.; Alexiou, K.; Stumpf, J.; Kappert, U.; Matschke, K. Surgical cut-down or percutaneous access-which is best for less vascular access complications in transfemoral TAVI? Catheter. Cardiovasc. Interv. 2016, 88, E52-E58. [CrossRef] [PubMed] 